Int. J. Mol. Sci. 2003, 4, 572-585

International Journal of

Molecular Sciences

ISSN 1422-0067

(C) 2003 by MDPI

www.mdpi.org/ijms/

\title{
Cationic Polymerization of 1,2-Epoxypropane by an Acid Exchanged Montmorillonite Clay in the Presence of Ethylene Glycol
}

\author{
Ahmed Yahiaoui, Mohammed Belbachir*, and Aïcha Hachemaoui \\ Laboratoire de chimie des polymères, Département de Chimie, Faculté des Sciences, Université \\ d’Oran, BP 1524 El’Menouer Oran 31000 Algérie. Fax:213 415100 57, E-mail: yahmeddz@yahoo.fr
}

Received: 7 May 2003 / Accepted: 14 October 2003 / Published: 27 October 2003

\begin{abstract}
The polymerization of propylene oxide (PO) catalysed by maghnite- $\mathrm{H}^{+}\left(\mathrm{mag}-\mathrm{H}^{+}\right)$ in the presence of ethylene glycol was investigated. $\mathrm{Mag}-\mathrm{H}^{+}$is a montmorillonite silicate sheet clay was prepared through a straight forward proton exchange process. It was found that the cationic polymerization of PO was initiated by mag- $\mathrm{H}^{+}$at $20{ }^{\circ} \mathrm{C}$ both in bulk and in solution. The effect of the amount of mag- $\mathrm{H}^{+}$and solvent was studied. These results indicated the cationic nature of the polymerization A possible initiation pathway, via the transfer of protons from mag- $\mathrm{H}^{+}$to the monomer, is proposed.
\end{abstract}

Keywords: maghnite, montmorillonite, catalyst, epoxides, propylene oxide, ring opening polymerization.

\section{Introduction}

Montmorillonite is a naturally occurring clay which has the ideal formula $\mathrm{Al}_{2} \mathrm{O}_{3} \cdot \mathrm{SiO}_{2} \cdot \mathrm{HOH}+\mathrm{nH}_{2} \mathrm{O}$. When pre-treated with strong acids, the mineral may be used, for example, as a bleaching clay or in reactions which would otherwise be catalysed using proton or Lewis acids, such as the polymerizations of tetrahydrofuran [1] and epoxides [2]. Recently, monomers were found to intercalate into lattice layers of montmorillonite clay, permitting in situ polymerizations yielding polymer/clay nanocomposites. Several polymers, for example, polyamide (nylon-6) [3], polystyrene (PS) [4-8], and polystyrene-block-polyisoprene-block-polystyrene[9], have been prepared via this route.

The cationic polymerization of epoxides, in the presence of hydroxyl-containing compounds, proceeds via two competitive mechanisms [10-18]: 
(i) the active chain end mechanism (ACEM) in which three membered cyclic tertiary oxonium ions constitute the growing species, as detailed in Scheme 1 (a). Propagation is accompanied in this case by end-biting and back-biting reactions, giving rise to cyclics (di-, tri- or tetramer, depending on the epoxide used); and

(ii) the activated monomer mechanism (AMM) in which propagation involves the addition of an activated (e.g., protonated) monomer onto the hydroxyl end-group of the initiator or the growing macromolecule, as shown in Scheme 1 (b).

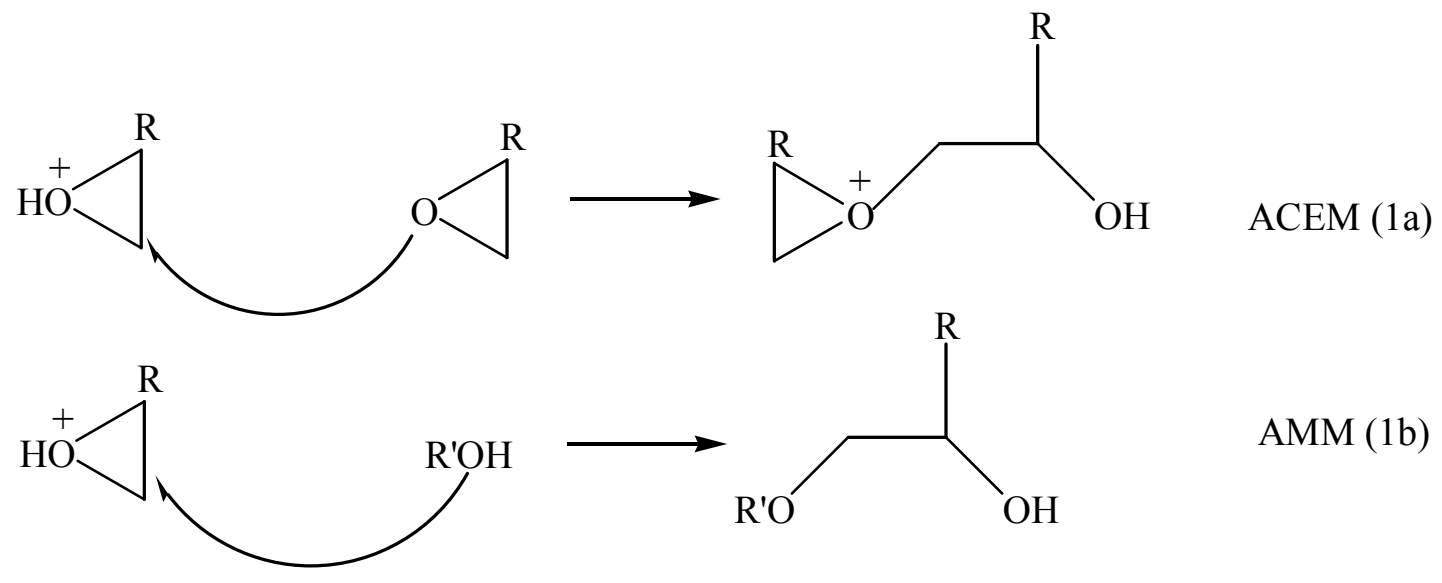

( $\mathrm{R}^{\prime} \mathrm{OH}$ : initiator or growing macromolecules)

\section{Scheme 1}

In order to limit the formation of cyclic oligomers in these reactions and therefore reduce the possibility of the reaction following the pathway shown in Scheme 1(a), it is necessary to add the monomer slowly to the reaction medium so as to increase the probability that the monomer will be protonated and then go on to react with the present nucleophiles. If, as here, the chain end of the epoxide polymer is an alcohol, the addition of the protonated monomer effectively leads to the reformation of the alcohol chain end. If this is the dominant process, the formation of cyclic oligomers may be suppressed. It is worth noting that using a diol as initiator and $\mathrm{HBF}_{4}$ as catalyst, Penczek prepared telechelic oligomers of epichlorohydrin and propylene oxide (PO) [19,20].

The cationic polymerization of alternative epoxides in the presence of diols have also been studied. For example, Xu et al. [21] studied the case of 1,2-epoxy-3-nitropropane (ENP) with 1,3-butane-diol as initiator. The authors indicated the formation of oligomers with $\mathrm{M}_{\mathrm{n}}=1100 \mathrm{~g} \mathrm{~mol}^{-1}$, however, the end groups of these systems were not presented. Poly(propylene oxide) (PPO), another 1,2-epoxide, is widely used in industrial applications. For example, PPO diols and higher polyols are used for the preparation of polyurethanes and polyurethane elastomers. However, the cationic initiators used to make PPO are expensive and often give rise to impurities, such as chromium, mercury or antimony, in the end product which often render the material unsuitable for medical or veterinary applications and make its disposal in the environment problematic. In addition, such initiators require the use of very 
high or very low temperatures and high pressures during the polymerization reaction, and lead to relatively poor yields.

The purpose of this paper is to study the cationic polymerisation of PO using a montmorillonite clay which has undergone a proton exchange process $\left(\right.$ mag- $\left.\mathrm{H}^{+}\right)$, a new, non-toxic cationic catalyst for heterocyclic monomers [22]. In contrast to the more usually used catalysts, mag- $\mathrm{H}^{+}$can be easily separated from the polymer and regenerated by heating to a temperature above $100{ }^{\circ} \mathrm{C}[23,24]$. The effects of the relative amounts of mag- $\mathrm{H}^{+}$and solvent used, and eventually, the mechanism, are discussed.

\section{Experimental}

\section{Materials}

1,2-Propylene oxide (PO) and ethylene glycol (EG) were purified by fractional distillation. Dichloromethane and toluene were purified following standard techniques and used after distilling over their respective drying agents. These chemical were obtained from Aldrich.

Montmorillonite clay, or 'raw-maghnite' was obtained from ENOF Maghnia (Western of Algeria). The protonated forms of montmorillonite $\left(\operatorname{mag}-\mathrm{H}^{+}\right)$were prepared by shaking the clay in a solution of sulfuric acid until saturation was achieved (normally after $2 \mathrm{~d}$ at room temperature). The cationexchanged clay was then recovered by filtration, and again suspended in deionized water. This process was repeated until no sulfate ions were indicated present in the filtrate using $\mathrm{BaCl}_{2}$. The mag- $\mathrm{H}^{+}$was then isolated by filtration, dried at $105^{\circ} \mathrm{C}$ and then finely ground. The cation exchange capacity (CEC) of the clay was found to be $84 \mathrm{mEq}(100 \mathrm{~g})^{-1}$ of dried clay. Sulfuric acid of concentrations $0.05 \mathrm{M}$, $0.10 \mathrm{M}, 0.15 \mathrm{M}, 0.20 \mathrm{M}, 0.25 \mathrm{M}, 0.30 \mathrm{M}$ and $0.35 \mathrm{M}$ were used to prepare the samples, respectively, denoted mag- $\mathrm{H}^{+} 0.05 \mathrm{M}$, mag- $\mathrm{H}^{+} 0.10 \mathrm{M}, \operatorname{mag}-\mathrm{H}^{+} 0.15 \mathrm{M}$, mag- $\mathrm{H}^{+} 0.20 \mathrm{M}, \operatorname{mag}-\mathrm{H}^{+} 0.25 \mathrm{M}, \operatorname{mag}-\mathrm{H}^{+}$ $0.30 \mathrm{M}$ and mag- $\mathrm{H}^{+} 0.35 \mathrm{M}$.

Polymerizations were performed with or without dichloromethane at $20{ }^{\circ} \mathrm{C}$. The procedure was identical in both cases, involving slow addition of PO to the stirred bulk EG containing catalyst or the solution in dichloromethane. Prior to use, mag- $\mathrm{H}^{+}$was dried at $120{ }^{\circ} \mathrm{C}$ overnight and then transferred to a vacuum desiccator containing $\mathrm{P}_{2} \mathrm{O}_{5}$ to cool to room temperature overnight. An example reaction is detailed here. After charging the reaction vessel with the mineral (0.1g) and EG (0.086 mol), PO (10 g, $0.172 \mathrm{~mol}$ ) was slowly added. At the required time, an aliquot of the reaction mixture was then taken in such manner as to exclude any clay mineral. At the end of the reaction, the resulting mixture was dissolved in dichloromethane, filtered to remove the clay and then dried under vacuum to yield the polymer (yield of this example was $77 \%$ ). 


\section{Characterization}

Viscosity-average molecular weights $\left(\mathrm{M}_{\vee} \mathrm{s}\right)$ and intrinsic viscosity $(\eta)$ measurements were performed at $35{ }^{\circ} \mathrm{C}$ in toluene using a Sematech ${ }^{\circledR}$ (Viscologic TL1) capillary viscometer. Gel permeation chromatography (GPC) was performed using a Waters ${ }^{\circledR}$ model 200 instrument equipped with 4 styragel columns in series $\left(10^{3} \AA, 10^{4} \AA, 1.5 \times 10^{5} \AA\right.$ and $\left.3 \times 10^{6} \AA\right)$. Tetrahydrofuran was used as eluent at a flow rate of $1 \mathrm{~mL} \mathrm{~min}^{-1}$, and characterizations were performed against a series of 9 poly(ethylene oxide) standards. Hydroxyl groups were determined by reacting the solution of polymer in $\mathrm{CDCl}_{3}$ with a 2 fold excess of $\left(\mathrm{CF}_{3} \mathrm{CO}\right)_{2} \mathrm{O}$, followed by determination of $\mathrm{CF}_{3} \mathrm{COOCH}_{2}-(4.20 \mathrm{ppm} \delta)$ and $\mathrm{CF}_{3} \mathrm{COOCH}-(5.17 \mathrm{ppm} \delta)$ groups. Thermal gravimetric (TGA) characterisations were performed under nitrogen using a Dupont model 9900 thermal analyser at a heating rate of $20{ }^{\circ} \mathrm{C} \mathrm{min}^{-1}$.

Maghnite and mag- $\mathrm{H}^{+}$samples were characterised by XRF (a Philips PW 2400XRF spectrometer at the Laboratory of Inorganic Chemistry, Granada University, Spain) using the $\mathrm{LiB}_{4} \mathrm{O}_{7}$ fusion method. XRD profiles for pressed powder samples were recorded on a Philips PW 1710 diffractometer using $\mathrm{Cu}-\mathrm{K} \alpha$ radiation $(\lambda=1.5418 \AA)$. IR absorption spectra were recorded on a ATI Matson FTIR $\mathrm{N}^{\circ} 9501165$ spectrometer using the $\mathrm{KBr}$ pressed discs which were made up of $0.5 \mathrm{mg}$ of sample in 300 mg KBr. High-resolution solid-state ${ }^{29} \mathrm{Si}$ and ${ }^{27} \mathrm{Al}$ MAS NMR spectra of untreated (raw-maghnite) and acid treated $\left(\operatorname{mag}-\mathrm{H}^{+} 0.25 \mathrm{M}\right)$ samples were recorded on a Brüker ASX 500 spectrometer at 59.6 and 130.3 MHz, respectively. The sample spinning frequency was $4 \mathrm{KHz}$ for ${ }^{29} \mathrm{Si}$ and $11.5 \mathrm{KHz}$ for ${ }^{27} \mathrm{Al}$.

\section{Results and Discussion}

\section{Catalyst Structure}

Various methods of analysis, such as ${ }^{27} \mathrm{Al}$ and ${ }^{29} \mathrm{Si}$ MAS NMR, show that Maghnite is a montmorillonite sheet silicate clay. The elementary analysis of the selected samples obtained using $\mathrm{XRF}$ is as settled in the following Table 1. It is necessary to report that the best value of PO conversion obtained with mag- $\mathrm{H}^{+} 0.25 \mathrm{M}$, for this reason we kept this sample to study the effect of catalyst proportions and solvent on PO polymerization. Acid treatment of raw-maghnite was indicated to cause a relative reduction in the content of octahedrally spaced $\mathrm{Al}_{2} \mathrm{O}_{3}$ and a relative increase in silica $\left(\mathrm{SiO}_{2}\right)$.

Table 2 shows the various types of montmorillonites studied, and can see that Maghnite has $11.9 \%$ more $\mathrm{SiO}_{2}$ than that from Wyoming 19.35 than from Montmorillon (Vienne, French). When treated with sulfuric acid, this difference is even greater; $14.21 \%$ and $21.66 \%$ as compared to Wyoming and Vienne Bentonite, respectively. Maghnite contains 5.60\% and $5.49 \%$ less $\mathrm{Al}_{2} \mathrm{O}_{3}$, than the Wyoming and Vienne Bentonites, respectively.

Figures 1(a) and 1(b) and Table 3 show X-ray diffraction patterns of raw-maghnite and Mag- $\mathrm{H}^{+}$. The basal spacing of the raw-Maghnite was exhibited $15.02 \AA$. The titration of raw-maghnite with 0.25 $\mathrm{H}_{2} \mathrm{SO}_{4}$ resulted in the exchange of exchangeable cations for $\mathrm{H}^{+}$in the interlayer. The X-ray powder diffraction of the dried Mag- $\mathrm{H}^{+}$, as shown in Figure 1(b), exhibited $00 l$ reflections corresponding to 
Table1. Elementary compositions of Protons exchanged samples "Maghnite" compositions wt\%.

\begin{tabular}{lccccccccccc}
\hline & \multicolumn{10}{c}{ Composition $\mathrm{wt}^{\%}$} \\
\cline { 2 - 12 } & $\mathrm{SiO}_{2}$ & $\mathrm{Al}_{2} \mathrm{O}_{3}$ & $\mathrm{Fe}_{2} \mathrm{O}_{3}$ & $\mathrm{CaO}$ & $\mathrm{MgO}$ & $\mathrm{Na}_{2} \mathrm{O}$ & $\mathrm{K}_{2} \mathrm{O}$ & $\mathrm{TiO}_{2}$ & $\mathrm{SO}_{3}$ & $\mathrm{As}$ & $\mathrm{PF}^{*}$ \\
\hline Raw-Maghnite & 69.39 & 14.67 & 1.16 & 0.30 & 1.07 & 0.50 & 0.79 & 0.16 & 0.91 & 0.05 & 11 \\
H-Mag0.05M & 70.75 & 14.67 & 1.05 & 0.30 & 1.01 & 0.49 & 0.78 & 0.16 & 0.75 & 0.04 & 10 \\
H-Mag0.10M & 71.00 & 14.60 & 1.00 & 0.30 & 0.98 & 0.39 & 0.78 & 0.16 & 0.55 & 0.04 & 10 \\
H-Mag0.15M & 71.58 & 14.45 & 0.95 & 0.29 & 0.91 & 0.35 & 0.77 & 0.15 & 0.42 & 0.03 & 10 \\
H-Mag0.20M & 71.65 & 14.20 & 0.80 & 0.28 & 0.85 & 0.30 & 0.77 & 0.15 & 0.39 & 0.01 & 10 \\
H-Mag0.25M & 71.70 & 14.03 & 0.71 & 0.28 & 0.80 & 0.21 & 0.77 & 0.15 & 0.34 & 0.01 & 11 \\
H-Mag0.30M & 73.20 & 13.85 & 0.70 & 0.27 & 0.78 & 0.20 & 0.76 & 0.13 & 0.31 & 0.02 & 9.78 \\
H-Mag0.35M & 75.31 & 13.52 & 0.71 & 0.26 & 0.78 & 0.18 & 0.75 & 0.13 & 0.32 & 0.01 & 8.03 \\
\hline
\end{tabular}

*PF: Pert in Fire

Table 2. Comparison in the composition (in \%) of American, French and Maghnia Algerian Bentonites.

\begin{tabular}{lcccc}
\hline & $\begin{array}{c}\text { Wyoming } \\
\text { (USA)[25] }\end{array}$ & $\begin{array}{c}\text { Vienne } \\
\text { (France)[26] }\end{array}$ & $\begin{array}{c}\text { Raw-Maghnite } \\
\text { (Algeria) }\end{array}$ & $\begin{array}{c}\text { H-Maghnite } \\
\text { (Algeria) }\end{array}$ \\
\hline $\mathrm{SiO}_{2}$ & 50.04 & 57.49 & 69.39 & 71.70 \\
$\mathrm{Al}_{2} \mathrm{O}_{3}$ & 20.16 & 20.27 & 14.67 & 14.03 \\
$\mathrm{Fe}_{2} \mathrm{O}_{3}$ & 0.68 & 2.92 & 1.16 & 0.71 \\
$\mathrm{FeO}$ & & 0.19 & & \\
$\mathrm{CaO}$ & 1.46 & 0.23 & 0.30 & 0.28 \\
$\mathrm{MgO}$ & 0.23 & 3.13 & 1.07 & 0.80 \\
$\mathrm{~K}_{2} \mathrm{O}$ & 1.27 & 0.28 & 0.79 & 0.77 \\
$\mathrm{Na}_{2} \mathrm{O}$ & $\mathrm{Tr}$ & 1.32 & 0.5 & 0.21 \\
$\mathrm{TiO}_{2}$ & & 0.12 & 0.16 & 0.15 \\
$\mathrm{SO}_{3}$ & & & 0.91 & 0.34 \\
$\mathrm{As}$ & & & 0.05 & 0.01 \\
\hline
\end{tabular}

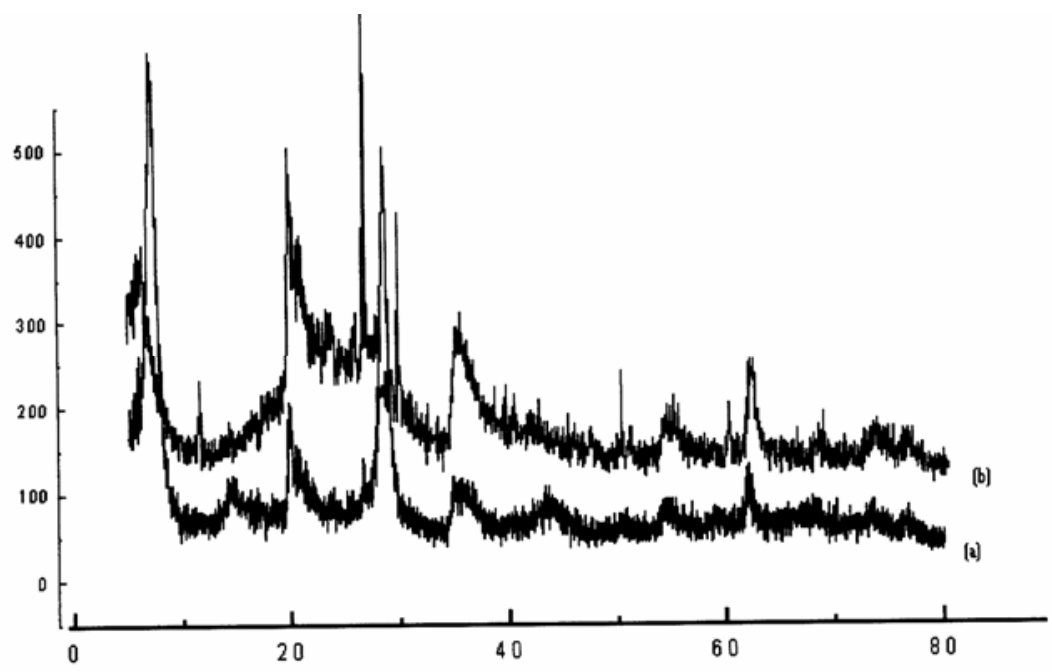

Figure 1. X-ray Power Diffraction of (a) "Raw-Maghnite" and (b) "Mag- $\mathrm{H}^{+} 0.25 \mathrm{M}$ " 
Table 3: RX characteristic of Raw-Maghnite and Mag- $\mathrm{H}^{+} 0.25 \mathrm{M}$.

\begin{tabular}{|c|c|c|c|}
\hline Samples & $\mathrm{d}_{\mathrm{hkl}}\left(\mathrm{A}^{\circ}\right)$ & hkl & Nature of sample \\
\hline \multirow[t]{9}{*}{ Raw-Maghnite } & 12.50 & 001 & Montmorillonite \\
\hline & 4.47 & 110 & Montmorillonite \\
\hline & 4.16 & , & Quartz \\
\hline & 3.35 & , & Quartz \\
\hline & 3.21 & , & Feldspath \\
\hline & 3.03 & , & Calcite \\
\hline & 2.55 & 200 & Montmorillonite \\
\hline & 1.68 & 009 & Montmorillonite \\
\hline & 1.49 & 060 & Montmorillonite \\
\hline \multirow[t]{9}{*}{$\mathrm{Mag}-\mathrm{H}^{+} 0.25 \mathrm{M}$} & 15.02 & 001 & Montmorillonite \\
\hline & 4.47 & 110 & Montmorillonite \\
\hline & 4.16 & , & Quartz \\
\hline & 3.35 & ", & Quartz \\
\hline & 3.21 & , & Feldspath \\
\hline & 3.03 & , & Calcite \\
\hline & 2.55 & 200 & Montmorillonite \\
\hline & 1.68 & 009 & Montmorillonite \\
\hline & 1.49 & 060 & Montmorillonite \\
\hline
\end{tabular}

basal spacing of $12.5 \AA$. Yun Kwon et al[27] reported that the decrease in the basal spacing indicates a loss of the interlayer $\mathrm{H}_{2} \mathrm{O}$ upon the replacement of $\mathrm{Na}^{+}$for $\mathrm{H}^{+}$. In particular, although the X-ray peak of the montmorillonite did not change substantially before or after the acid treatment, there was a decrease in the basal spacing. This implies that the original structure was well preserves after the acid treatment.

The effects of the acid activation process on the FTIR spectrum of the treated Maghnite (Fig. 2) are summarised as follows: The intensity of the absorption band at $3630 \mathrm{~cm}^{-1}$ (AlAlOH coupled by $\mathrm{AlMgOH}$ stretching vibrations) decreases with acid treatment. The bands at $3425 \mathrm{~cm}^{-1}$ and $3200 \mathrm{~cm}^{-1}$ (absorption of interlayer water) become more diffuse with acid treatment [28]. The intensity of the SiO out of plane and Si-O-Si (2 bands) in plane stretching bands at 1116, 1043 and $999 \mathrm{~cm}^{-1}$ have not been affected by acid treatment. The AlAlOH $\left(920 \mathrm{~cm}^{-1}\right), \mathrm{AlFe}{ }^{3+} \mathrm{OH}\left(883 \mathrm{~cm}^{-1}\right)$ and AlMgOH $(846$ $\mathrm{cm}^{-1}$ ) deformation bands decrease with acid treatment. The intensity of the band at $796 \mathrm{~cm}^{-1}$ increases with treatment, reflects alterations in the amount of amorphous silica in accordance to the findings of others workers $[29,30]$. The intensity of the band at $628 \mathrm{~cm}^{-1}$ (either Al-OH or Si-O bending and / or Al-O stretching vibration) gradually decreases with acid treatment in good agreement with the findings of Komadel [31]. The intensity of the band at $467 \mathrm{~cm}-1$ (Si-O-Al and Si-O-Mg coupled by $\mathrm{OH}$ vibration or Si-O bending vibrations) is essentially unchanged. 


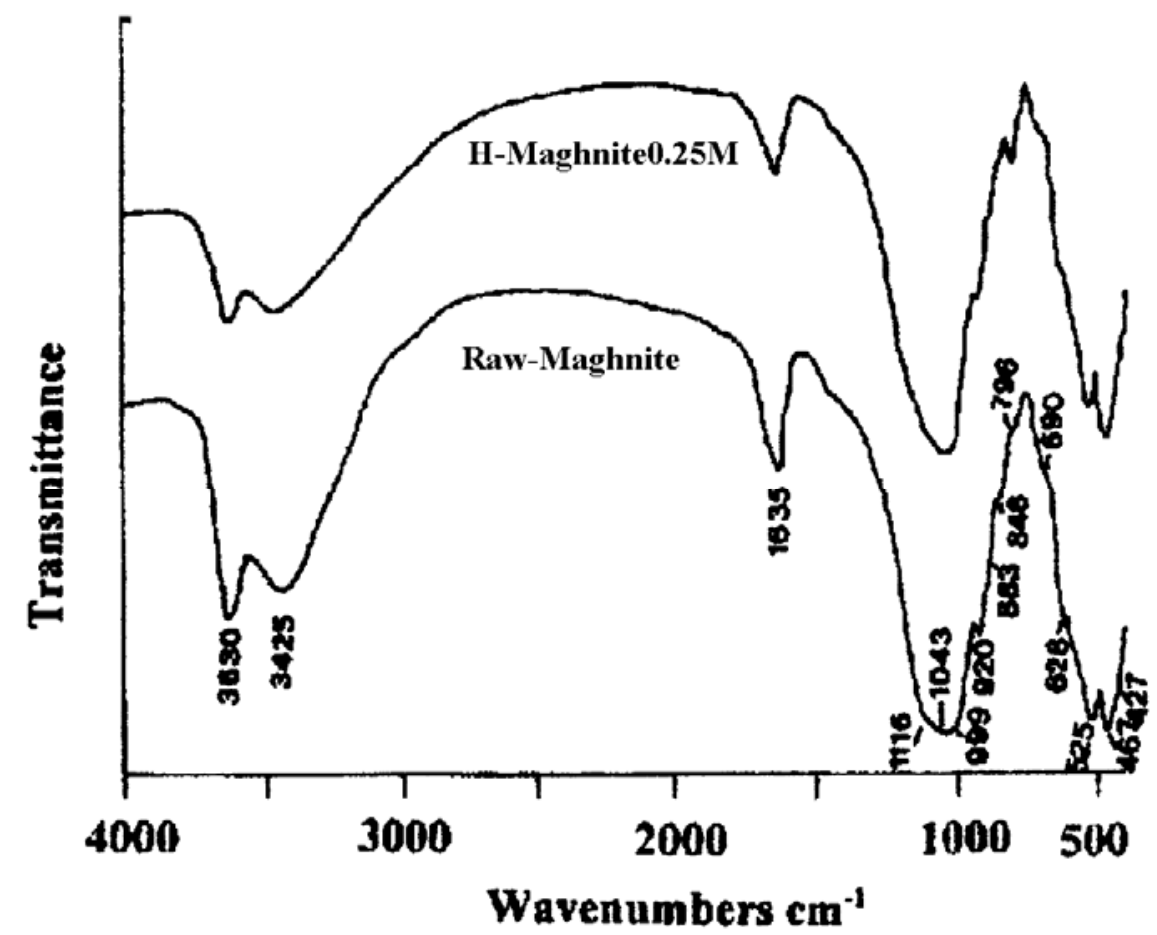

Figure 2. IR Spectra of (a) untreated Clay "Raw-Maghnite" and (b) Acid treated Clay "Mag$\mathrm{H}^{+} 0.25 \mathrm{M} "$

${ }^{27} \mathrm{Al}$ NMR spectra of both raw-maghnite and mag- $\mathrm{H}^{+} 0.25 \mathrm{M}$ are given in Fig 3 . The spectra of Maghnite exhibits mainly the typical resonance at $2.9 \mathrm{ppm}$ of octahedral aluminium $\left({ }^{[6]} \mathrm{Al}\right)$ in a phyllosilicate but also a small but significant contributions at 60 and $68 \mathrm{ppm}$ assigned to aluminium tetrahedrally co-ordinated to oxygen $\left({ }^{[4]} \mathrm{Al}\right)[32,33]$.

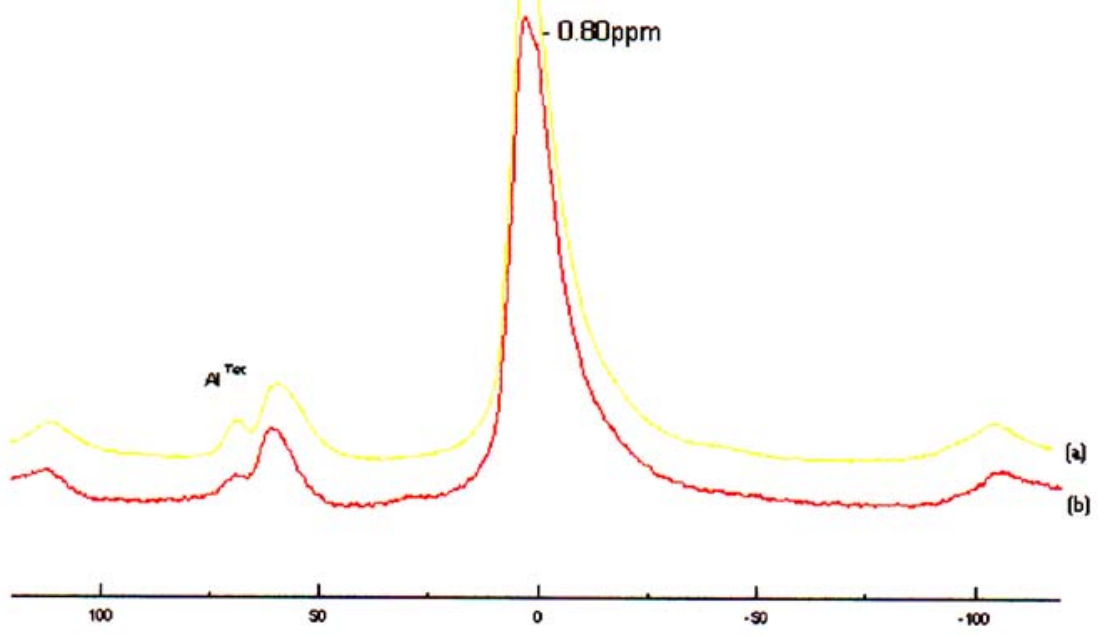

Figure 3. ${ }^{27} \mathrm{Al}$ MAS NMR spectra of (a) "Raw-Maghnite" and (b) "Mag- $\mathrm{H}^{+} 0.25 \mathrm{M}$ " 
The ${ }^{29} \mathrm{Si}$ MAS NMR spectra for the raw-maghnite and Mag- $\mathrm{H}^{+} 0.25 \mathrm{M}$ are shown in Fig 4 . The dominant resonance at $-93.5 \mathrm{ppm}$ corresponds to $\mathrm{Q} 3$ (OAl) units, i.e. $\mathrm{SiO}_{4}$ groups cross linked in the tetrahedral sheets with no aluminium in the neighbouring tetrahedral [34]. The resonance at $-112 \mathrm{ppm}$ corresponds to three-dimensional (3D) silica with no aluminium present, designed Q 4 (OAl) [27,34].

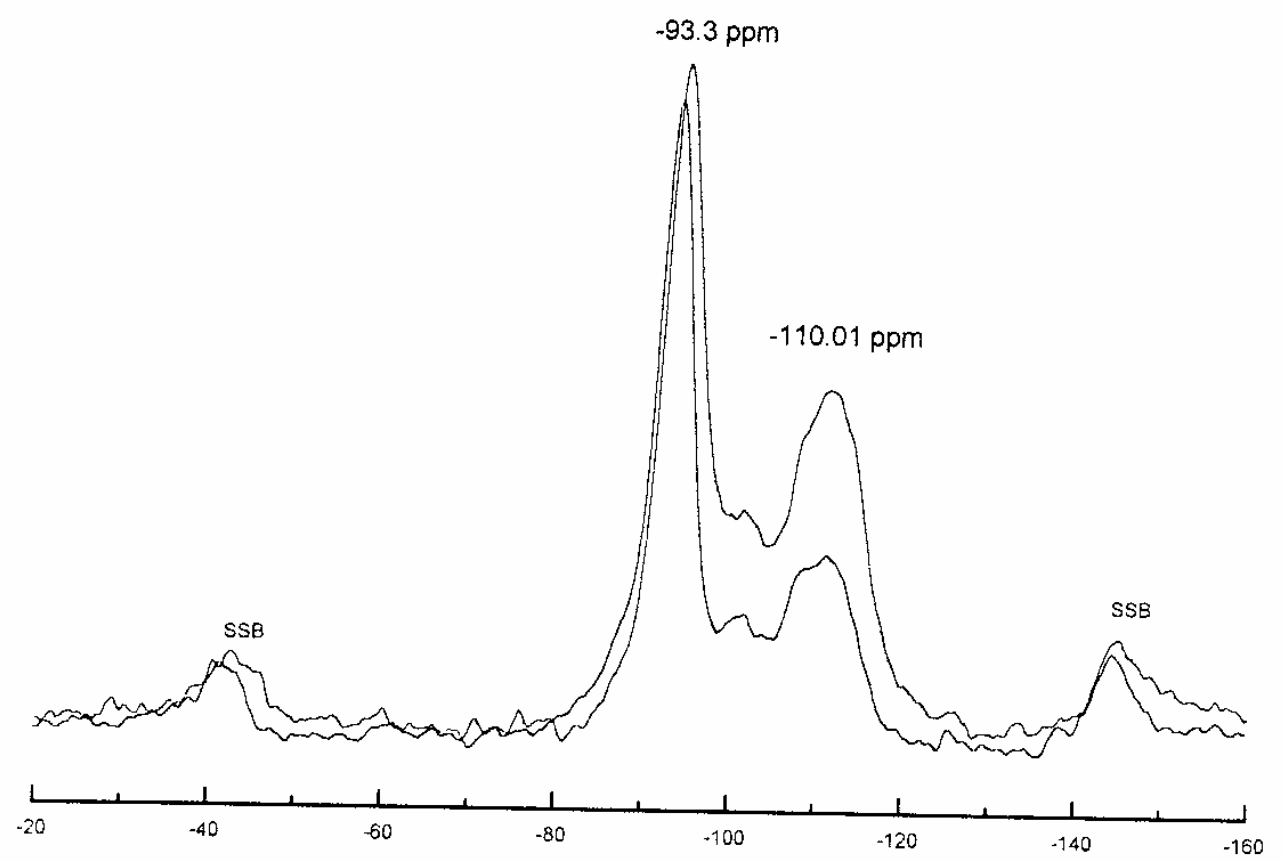

Figure 4. ${ }^{29} \mathrm{Si}$ MAS NMR spectra of (a) "Raw-Maghnite" and (b) "Mag- $\mathrm{H}^{+} 0.25 \mathrm{M}$ "

\section{Polymerization and Products Characterization}

The results of experiments of PO polymerization induced by $\mathrm{Mag}-\mathrm{H}^{+} 0.25 \mathrm{M}$ are reported in Table 4. For all these experiments the temperature was kept constant at $20^{\circ} \mathrm{C}$ for $2 \mathrm{~h}$.

Table 4. Polymerization of $\mathrm{PO}$ induced by the "Mag- $\mathrm{H}^{+} 0.25 \mathrm{M}$ "

\begin{tabular}{ccccccccc}
\hline Experiment & $\mathrm{PO}(\mathrm{g})$ & {$[\mathrm{PO}]$} & "H-Maghnite0.25M"(g) & Yield \% & $\mathrm{Mv}$ & $\mathrm{M}_{\mathrm{n}}$ & $\mathrm{M}_{\mathrm{w}}$ & $\mathrm{I}=\mathrm{M}_{\mathrm{w}} / \mathrm{M}_{\mathrm{n}}$ \\
\hline 1 (Bulk) & 10 & - & 0.1 & 15 & 520 & 349 & 771 & 2.21 \\
$2(\mathrm{Bulk})$ & 10 & - & 0.05 & 04 & 910 & 746 & 993 & 1.33 \\
$3\left(\mathrm{CH}_{2} \mathrm{Cl}_{2}\right)$ & 5 & 5 & 0.1 & 11 & 896 & 610 & 1050 & 1.72 \\
\hline
\end{tabular}

\section{Effect of Mag- $H^{+}$0.25M Proportion}

Table 5 and Figure 5 show the effect of the amount of $\mathrm{Mag}^{-\mathrm{H}^{+}}$on the polymerization rate of PO. As can be noted in this figure, the polymerization rate increased with the amount of Mag- $\mathrm{H}^{+}$. These results clearly indicate that an optimal rate of reaction is obtained at room temperature by polymerizing PO in bulk with Mag- $\mathrm{H}^{+}$proportion equal to $1 \%$. Under these conditions, monomer conversion reaches $80 \%$ 
Table 5. PO conversions with time: for $10 \mathrm{~g}$ of PO, the amounts of Mag- $\mathrm{H}^{+} 0.25 \mathrm{M}$ were: $\left.\left.\mathrm{a}\right) 0.1 \mathrm{~g}, \mathrm{~b}\right) 0.05 \mathrm{~g}$

\begin{tabular}{cccccccccc}
\hline Time(h) & 2 & 6 & 9 & 15 & 18 & 20 & 22 & 26 & 30 \\
\hline Yield(\%)(a) & 15 & 21 & 30 & 42 & 52 & 60 & 67 & 77 & 80 \\
Yield(\%)(b) & 4 & 15 & 26 & 30 & 35 & 39 & 50 & 52 & 54 \\
\hline
\end{tabular}

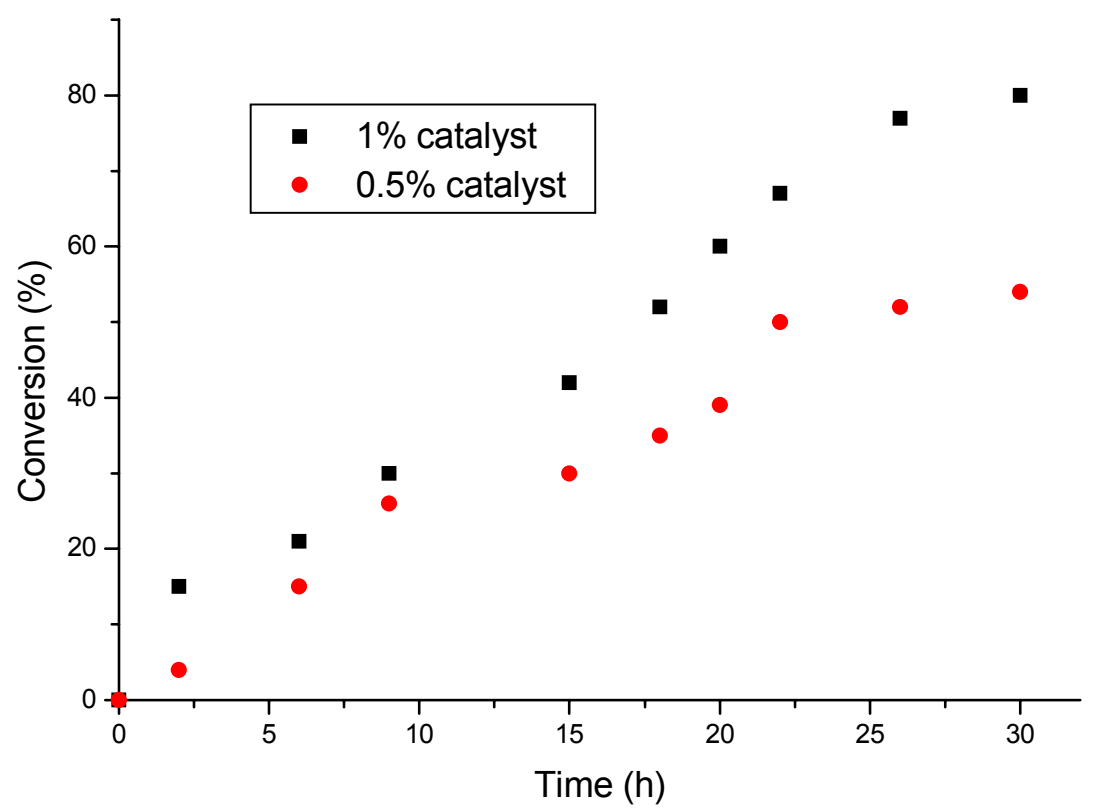

Figure 5. Effect of catalyst proportion upon the conversion of Propylene oxide.

after 30 h. Similar results are obtained by Belbachir et al[23,24], and Njopwouo et al[35], in the polymerization of $\mathrm{N}$-vinyl pyrrolidone and THF by $\mathrm{Mag}^{-} \mathrm{H}^{+}$and the polymerization of styrene by montmorillonite, respectively.

In contrast, as depicted in Figure 6, the molecular weight is inversely proportional to the amount of Mag-H. This finding is in good agreement with the proposal that Mag-H is present as the active initiator species since the number of those species should be related to their surface area. Similar results are obtained by Kadakowa et al. [36], and Crivello et al. [37], in the polymerization of lactones by Sn-montmorillonite and cyclohexene oxide by Cobalt respectively.

\section{${ }^{1}$ H-NMR Study}

An investigation was devoted to the analysis of the PPO by ${ }^{1} \mathrm{H}$ NMR spectroscopy at $200 \mathrm{MHz}$ (Table 6 and Fig. 7).
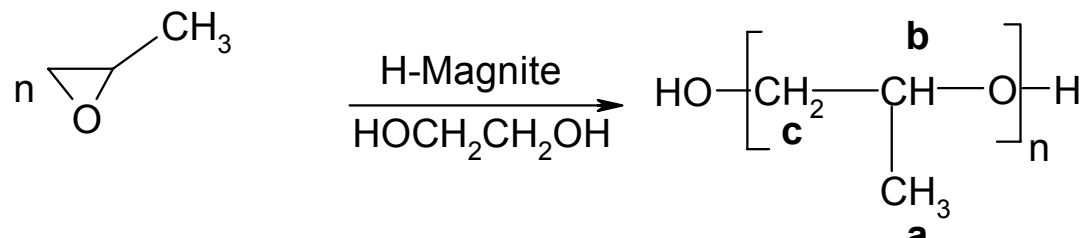

Scheme 2 


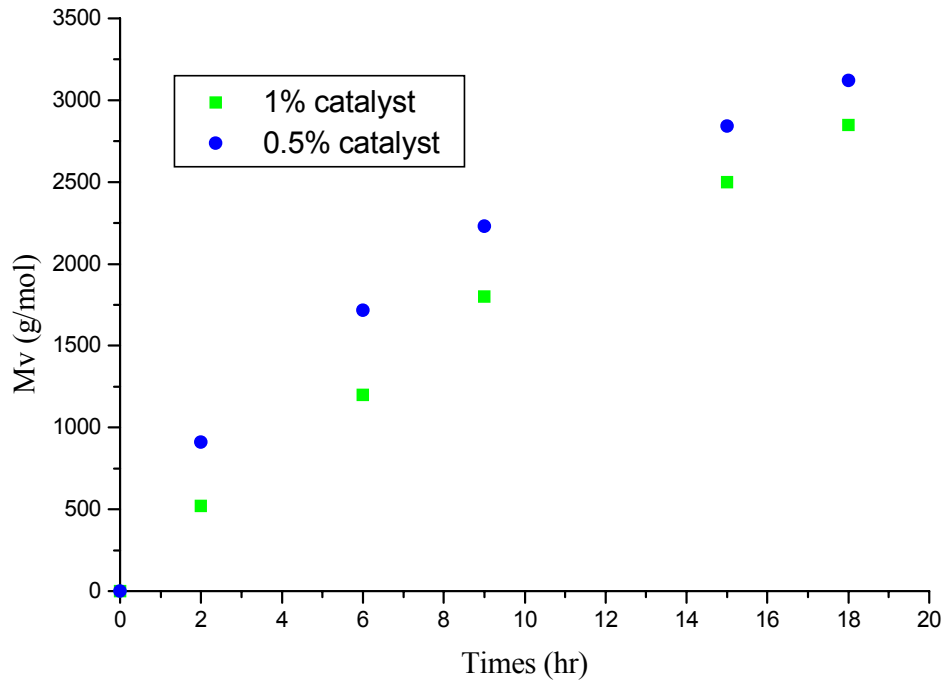

Figure 6. Effect of catalyst proportion upon the viscosimertic molecular weight.

Table 6. Chemical shift of polymers protons

\begin{tabular}{cccc}
\hline Proton type & (a) & (b) & (c) \\
\hline$\delta(\mathrm{ppm})$ & 1.1 & 3.5 & 3.5 \\
\hline
\end{tabular}

$$
\left[\begin{array}{c}
\text { (b) } \\
-\mathrm{CH}_{2}-\underset{\mathrm{C}}{\mathrm{C}}-\mathrm{o} \\
1 \\
\text { (a) } \mathrm{CH}_{3}
\end{array}\right] \mathrm{n}
$$

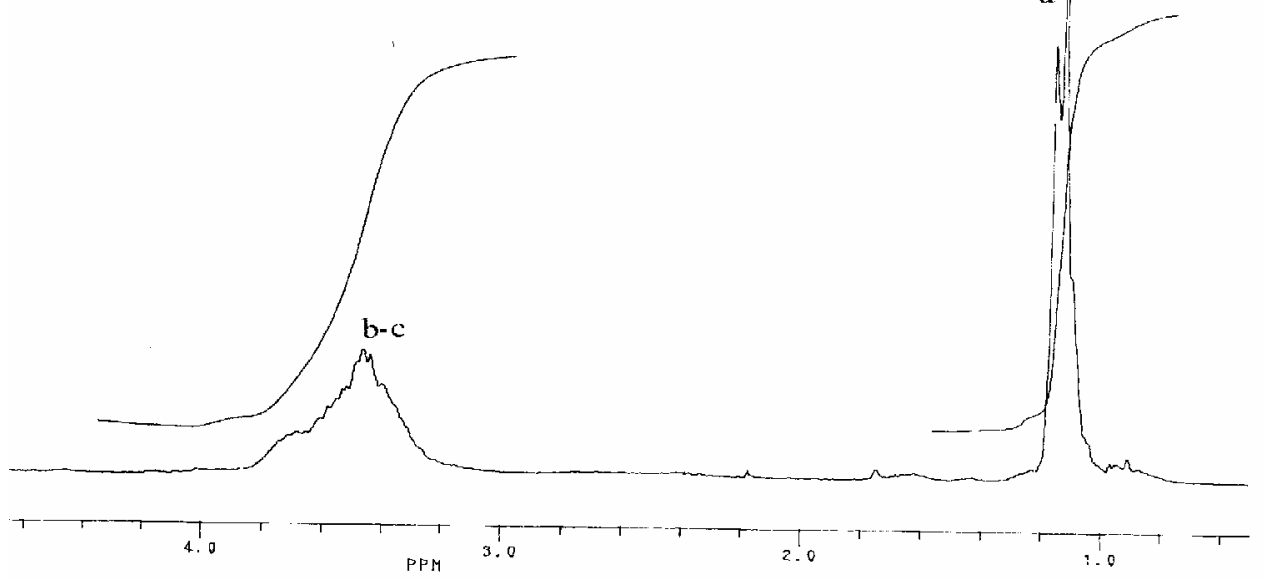

Figure 7. $200 \mathrm{MHz}{ }^{1} \mathrm{H}-\mathrm{NMR}$ spectrum of $\mathrm{PPO}$ in $\mathrm{CDCl}_{3}$. 
According to the work published by Oguni et al[38] and Ishimori et al[39] ${ }^{1} \mathrm{H}$ NMR spectroscopy at $200 \mathrm{MHz}$ (Solvent CDCl3) (Fig. 7) consist of a broad doublet centred at ca $1.1 \mathrm{ppm}$ $\left(\mathrm{CH}_{3}\right)$ and complex multiplet centred at ca. $3.5 \mathrm{ppm}\left(\mathrm{C}_{2} \underline{2}_{2} \mathrm{O}, \mathrm{C} \underline{\mathrm{H}}-\mathrm{O}\right)$.

\section{End-Groups}

${ }^{1}$ H-NMR method was used for the end-groups analysis. Two types of end-groups, primary and secondary hydroxyl groups may be present in PPO diols.<smiles>CC(C=O)CO</smiles><smiles>CC(O)C[O-]</smiles>

The signals of protons in the groups underlined in reaction (2) are to close to the corresponding signals from the chain, therefore hydroxyl end-groups were converted into the ester groups by reaction with trifluoroacetic anhydride. Thus, fourfold excess of $\left(\mathrm{CF}_{3} \mathrm{CO}\right)_{2} \mathrm{O}$ was added directly to the NMR tubes containing solution of PPO diol. The spectrum is shown in Fig. 8 together with the relevant assignment. A small doublet at $1.27 \mathrm{ppm}$ related to the methyl groups at the esterified hydroxyl groups $\mathrm{CF}_{3} \mathrm{COOCH}\left(\underline{\mathrm{CH}}_{3}\right) \mathrm{CH}_{2^{-}}$and $\mathrm{CF}_{3} \mathrm{COOCH}_{2} \mathrm{CH}\left(\underline{\mathrm{CH}}_{3}\right)^{-}$. The distorted doublet at $4.20 \mathrm{ppm}$ is due to the protons in methylene group $\mathrm{CF}_{3} \mathrm{COOCH}_{2} \mathrm{CH}\left(\mathrm{CH}_{3}\right)$ - and the sextet at $5.17 \mathrm{ppm}$ is due to the proton in the methine group $\mathrm{CF}_{3} \mathrm{COOCH}\left(\mathrm{CH}_{3}\right) \mathrm{CH}_{2-}$

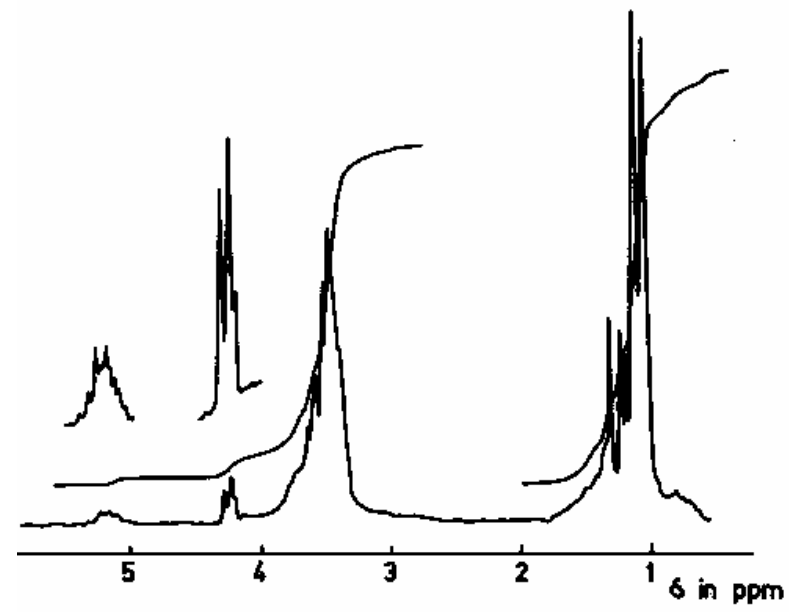

Figure 8. $200 \mathrm{MHz}{ }^{1} \mathrm{H}-\mathrm{NMR}$ spectrum of poly(propylene oxide) after esterification with $\left(\mathrm{CF}_{3} \mathrm{CO}\right)_{2} \mathrm{O}$ in $\mathrm{CDCl}_{3}$. 
The large amount of secondary hydroxyls shows that, for steric reasons, the activated monomer is preferentially attacked on the carbon atom located in the $\beta$ position with regard to the $\mathrm{CH}_{3}$ group, as it is illustrated below:

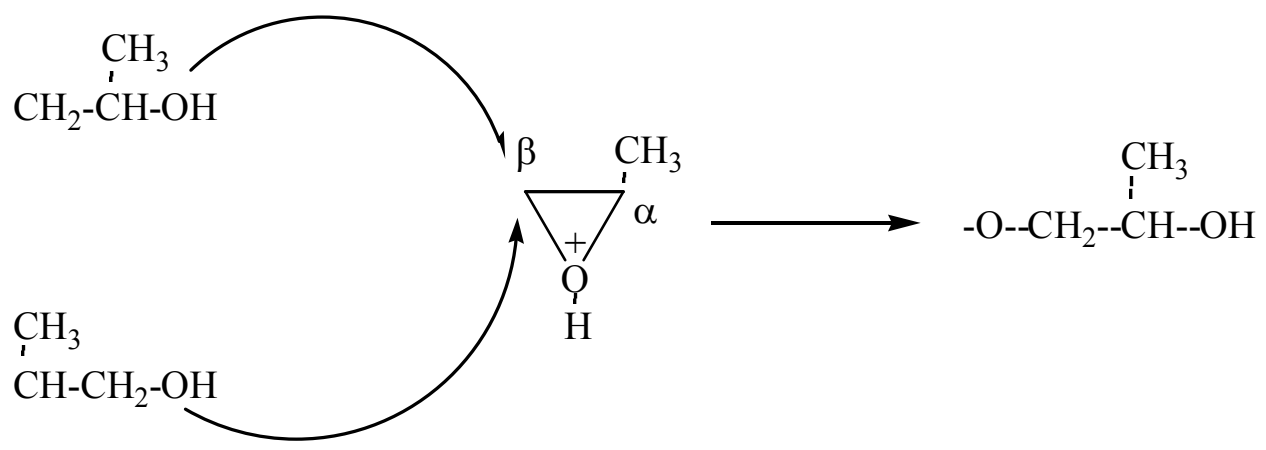

Similar results were obtained by Penczek and Lagarde in the case of epichlorhydrin and 1,2-epoxy3-nitropropane $[16,17]$.

\section{Effect of Solvent}

The data in Table 3 indicates that polymerizations carried out in solution leaded to higher molecular weights and narrower molecular weight distributions (MWDs) $\left(\mathrm{M}_{\mathrm{w}} / \mathrm{M}_{\mathrm{n}}\right)$. However, conversions in solution were smaller than the ones obtained in bulk polymerisation. Low conversions in solution polymerization may be explained by the difficult contact in heterogeneous phase, between monomer particles and the "initiating active sites" of "catalyst" surface.

\section{Polymerization Mechanism}

PO may be polymerized via a cationic pathway. According to the preceding discussion and the results of product analysis, we propose a cationic mechanism for the resulting reaction of polymerization initiated by Mag- $\mathrm{H}^{+} 0.25 \mathrm{M}$. Protons carried by montmorillonite sheets of Mag- $\mathrm{H}^{+}$ $0.25 \mathrm{M}$ initiated the cationic polymerization, these montmorillonite sheets take place as counteranions. Propagation then takes place by conventional cationic mechanism.

\section{Initiation}

Protons carried by montmorillonite sheets of Mag- $\mathrm{H}^{+} 0.25 \mathrm{M}$ induced the polymerization; these montmorillonite sheets take place as counter-anions.

The first stage is the protonation of PO. The formed ions oxonium take place in the vicinity of the counter-anion carried by montmorillonite sheets, as in:

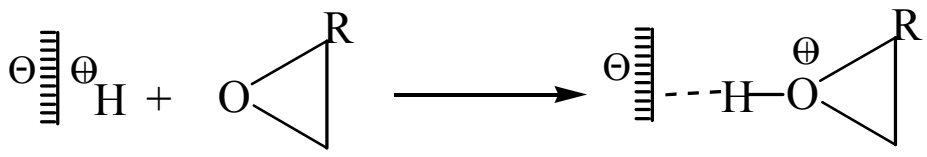




\section{Propagation}

Then a molecule of EG attacks in a nucleophilic way protonated PO.

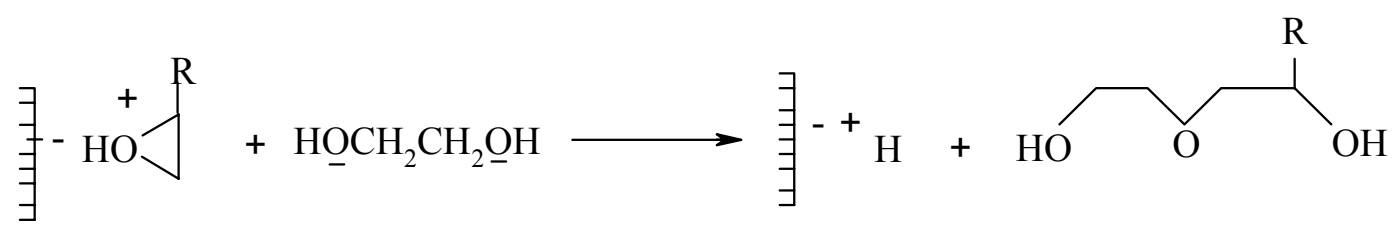

Subsequently, there is a nucleophilic attack of the oxygen of hydroxyl of the chains in growth on the carbon atom located in the $\beta$ position with regard to the $\mathrm{CH}_{3}$ group
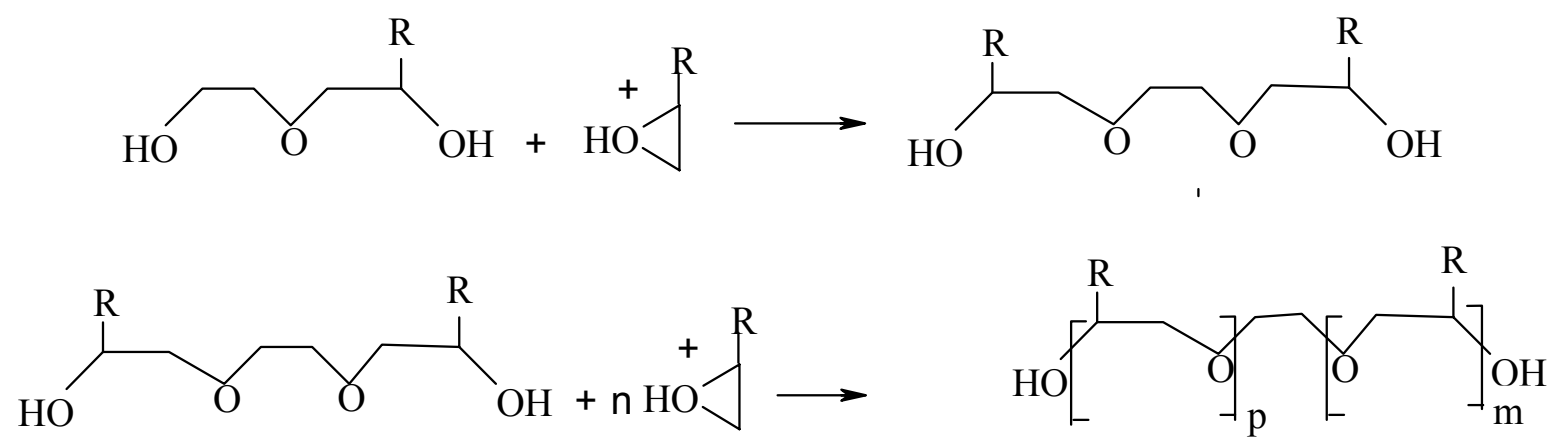

\section{Conclusion}

In conclusion, we have found that acid-exchanged maghnite is effective as acidic catalyst for the ring opening polymerization of PO. The polymerization catalysed by $\mathrm{Mag}-\mathrm{H}^{+}$, in the presence of ethylene glycol proceeds by activated monomer mechanism (AMM) to yield PPO. The polymerization proceeds smoothly, and a simple filtration is sufficient to recover the catalyst.

\section{Acknowledgements}

The authors wish to thank Dr. Roger Hiorns, University of Pau and Ador Region, for his support and encouragement.

\section{References}

1. Mueller, H.; Huchler, O. H and Hoffmann, H. US Patent. 1981, 4243799.

2. Farbenfabriken Bayer, German Patent. 1959, 1049103.

3. Fujita, K.; Ishida, Y and J.Suezana, Japan Kokai Tokkyo Toho, JP, 1987, 62289537.

4. Vu Moc, T.; Petit, H and Maitte, P. Bull. Soc. Belg, 1982, 91, 261.

5. Schelly, J. S.; Mather, P. T and DeVries, K. L. Polymer. 2001, 42, 5849.

6. Vaia, R. A.; Jandt, K. D.; Kramer, E. J and Giannelis, E. P. Macromolecules. 1995, 28, 8080. 
7. Vaia, R. A and Giannelis, E. P. Macromolecules. 1997, 30, 7990.

8. Yoon, J. T.; Jo, W. H.; Lee, M. S and Ko, M. B. Polymer. 2001, 42, 329.

9. Lee, J.; Park, M. S.; Yang, H. C.; Cho, K and Kim, J. K. Polymer. 2003, 44, 1705.

10. Dreyfuss, M. P. J. Macromol. Sci. Chem. 1975, A9, 729.

11. Kern, R. J. J.Org. Chem. 1968, 33, 388.

12. Libszowski, J.; Szymanski, R and Penczek, S. Makromol.Chem. 1989, 190, 1225.

13. Biedron, T.; Kubisa, P and Penczek, S. J. Polym. Sci.: Pt A: Polym Chem. 1991, 29, 619.

14. Tokar, R.; Kubisa, P.; Penczek, S and Dworak A. Macromolecules. 1994, 27, 320.

15. Bednarek, M.; Kubisa, P and Penczek, S. Makromol.Chem.Suppl . 1989, 15, 49.

16. Biedron, T.; Szymanski, R.; Kubisa, P.; Penczek, S. Makromol. Chem, Macromol. Symp. 1990, 32, 155.

17. Lagarde, F.; Reibel, L and Franta, E. Makromol.Chem. 1992, 193,1087.

18. Weiss, A. Angew. Chem. Int, Ed. 1981, 20, 850.

19. Wojtania, M.; Kubisa, P and Penczek, S. Makromol. Chem. Symp. 1986, 6, 201.

20. Kubisa, P. Makromol. Chem. Symp. 1988, 13/14, 203.

21. Xu, Y.; Dong, S.; Fan, C.; Wang, W.; Den, K and Zhow, M. Z. Gaoefenzi Tongxun. 1981, 5, 368.

22. Belbachir, M and A. Bensaoula, US Patent. 2001, 6274527 B1.

23. Meghabar, R.; Megherbi, A and Belbachir, M. Polymer (in press).

24. Ferrahi, M.I and Belbachir, M. Int. J. Mol. Sci. 2003, 4, 312.

25. Montmorillonite. Montmorillon (Vienne,France), Damour, An. Ph. Ch. 1847, 21, 376.

26. Bentonite, Upton, Wyoming (USA), Analytical Data Reference, Clay Min, Report № 7. Amer. Petro. Int. Project 49, 1950.

27. Yun Kwon, O.; Won Park, K and Young Jeong, S. Bull. Korean Chem. Soc. 2001, 22(7), 679.

28. Farmer, V. C. In Infrared Spectra of Minerals, Farmer, V. C., Ed, Mineralogical Society, London. 1974, 331 .

29. Moeke, H. H. W. In Infrared Spectra of Minerals, Farmer, V. C., Ed.; Mineralogical Society: London. 1974, 365.

30. Madejovà, J.; Bednànikovà, E.; Komadel, $\mathrm{P}$ and Cicel, B. in Proc.11 th Conf. Chem. Miner. Petrol.Ceske Budéjovica 1990; Konta, J., Ed., Charles University: Prague, 1993, 267.

31. Komadel, P. Clay Minerals. 2003, 38, 127.

32. Benharrats, N.; Belbachir, M.; Legran, A. P and D'espinose de le Caillerie, J. B. Clays Minerals. 2003, 38, 49.

33. Samajovà, E.; Kraus, I and Lajcàkovà, A. Geol. Carpath. Ser. Clays. 1992, 42, 21.

34. Tkàc, I.; Komadel P and Müle, D. Clay Miner. 1994, 29, 11.

35. Njopwouo, D.; Roques, G and Wandji, R. Clay Miner. 1987, 22, 45.

36. Kadokawa, J.; Iwasaki, Y and Tagaya, H. Green Chemistry. 2002, 4, 14.

37. Crivello, J. V and Fan, M. J. Polym. Sci. Part A. 1992, $30,1$.

38. Oguni, N.; Maeda, S and Tani, H. Macromolecules. 1973, 6, 459.

39. Ishimori, M.; Tsukigawa, T and Tsuruta, T. Makromol.Chem. 1976, 177, 1221.

(C) 2003 by MDPI (http://www.mdpi.org). Reproduction for noncommercial purposes permitted. 